\title{
CARBON-13 NMR SPECTRA OF CAROTENOIDS
}

\author{
G. P. Moss \\ Department of Chemistry, Queen Mary College, Mile End Road, London, E1 4NS, UK
}

\begin{abstract}
The ${ }^{13} \mathrm{C}$-NMR spectrum of $\beta$-carotene has been assigned using data from deuterium labelled samples, and cis vitamin A. A study of methyl $\beta$-apo carotenoates is consistant with this result. Spectra of derivatives of $\beta$-carotene, such as zeaxanthin, isozeaxanthin, violaxanthin and alloxanthin, have been analysed.

The stereochemistry of lutein is deduced from its spectrum to be trans between the 3 '-hydroxyl group and the polyene chain at C-6'. It is suggested that isomytiloxanthin has the alkyl groups at C-5 and C-6 of the cyclohexanone ring trans.

Cis double bonds give characteristic changes in the spectrum compared with that of the corresponding trans compound violeoxanthin is shown to be the 9 -cis isomer of violaxanthin. ${ }^{13} \mathrm{C}-{ }^{31} \mathrm{P}$ coupling over six bonds is observed with trans $\beta$ - $\mathrm{C}_{15}$ Wittig salt, but only over four bonds with the $c$ is isomer. The $15,15^{\prime}$-cis- $\beta$-carotene spectrum suggests a revision of the assignment of the phytoene spectrum.

Using the data from appropriate apo esters and other model compounds the spectra of capsorubin and azafrin are analysed. The absence of suitable model compounds as yet prevents a complete assignment of the fucoxanthin spectrum.
\end{abstract}

\section{INTRODUCTION}

One of the most important techniques for the characterisation, or structure determination of carotenoids is ${ }^{1} \mathrm{H}-\mathrm{NMR}$ spectroscopy. A recent review ${ }^{1}$ listed the readily identifiable signals from eighty different end groups occurring in natural carotenoids. Due to complex second order spinspin coupling in most cases only methyl signals are clearly distinguished without the use of the higher resolution possible with a $220 \mathrm{MHz}$ spectrometer or similar instrument. Thus characterisation often relies on only two or three signals per end group.

In principal ${ }^{13} \mathrm{C}$-NMR spectroscopy is a much more powerful technique for structure determination. ${ }^{2}$ Even though the first spectrum was observed in 1957 by Lauterbur the low natural abundance of ${ }^{13} \mathrm{C}(1.1 \%)$ and low sensitivity compared with ${ }^{1} \mathrm{H}(1.59 \%)$ has delayed its routine application until recently. The use of large sample tubes, CATed, pulsed spectra with Fourier transformation, and broad band proton decoupling allows ready measurement of ${ }^{13} \mathrm{C}$-NMR spectra. As yet, either quite large amounts (e.g. $100 \mathrm{mg}$ ) of pure carotenoids or long accumulation times (e.g. $24 \mathrm{hr}$ ) are needed. Once obtained, the spectra are relatively easy to interpret, although assignment may be difficult. Each signal is normally a sharp singlet with ${ }^{1} \mathrm{H}-{ }^{13} \mathrm{C}$ spin-spin coupling absent due to the decoupling, and ${ }^{13} \mathrm{C}-{ }^{13} \mathrm{C}$ spin-spin coupling absent because of the low probability of two ${ }^{13} \mathrm{C}$-atoms being adjacent to each other.

A number of different techniques may be used to assign ${ }^{13} \mathrm{C}$-NMR spectra. Characteristic chemical shift values may often be used to identify some signals (see Fig. 1) and will readily permit the separation of the signals into two groups, those derived from $\mathrm{sp}^{2}$ and those from $\mathrm{sp}^{3}$ hybridised carbon atoms. Data derived from model compounds is obviously useful. The number of hydrogen atoms attached to each carbon atom may be determined by re-running the spectrum under single frequency off-resonance (SFOR) conditions whereby a small residual coupling is observed between each proton and the carbon it is attached to. Thus methyl carbon signals appear as quartets, methylenes as triplets etc. Under carefully controlled conditions additional information may be obtained from SFOR conditions by means of second-order effects. Thus with $\alpha$-ionone not only could $\mathrm{C}-7$ be related to $\mathrm{C}-8$ using their ${ }^{1} \mathrm{H}-{ }^{1} \mathrm{H}$ spin-spin coupling, but also it was possible to relate $\mathrm{C}-7$ to
C- $6{ }^{3}$ Probably the most unambiguous method of assignment is by selective deuteration. A carbon atom so labelled will not normally be detected in the ${ }^{13} \mathrm{C}-\mathrm{NMR}$ spectrum. It was by this means that $\mathrm{C}-15$ of $\beta$-carotene was first assigned correctly. ${ }^{4}$

\section{B-CAROTENE}

The ${ }^{13} \mathrm{C}$-NMR spectrum of $\beta$-carotene (I) and some related compounds was reported by Roberts and coworkers in $19700^{5}$ Extensive studies since then have confirmed their assignment of the $\mathrm{sp}^{3}$ signals, but, as deuteration $^{4}$ and SFOR studies ${ }^{6}$ showed, the sp $^{2}$ signals need revision. It has become apparent that the assignment of polyene $\mathrm{sp}^{2}$ signals cannot be based on simple models.

The spectrum of vitamin A acetate can be readily related to $\beta$-carotene (Fig. 2). The only significant differences occurring with C-10, C-12, C-13, C-14 and, of course, C-15. We were able to assign $\mathrm{C}-11$ and $\mathrm{C}-12$ (but not between them) by means of $\left[11,12-{ }^{2} \mathrm{H}_{2}\right]$ vitamin $\mathrm{A}$ acetate and the associated isotope effect was noticed at C-9, C-10, C-13 and C-14. SFOR data identified C-5, C-6, C-9, C-13 which can also be recognised in the high resolution spectrum (Fig. 2) by their narrower line widths. The various alternative assignments were distinguished by the study of a number of $c i s$ isomers at the trisubstituted double bond. Methyl bixin and its all trans isomer (XX) was particularly diagnostic due to the strong polarisation of the polyene

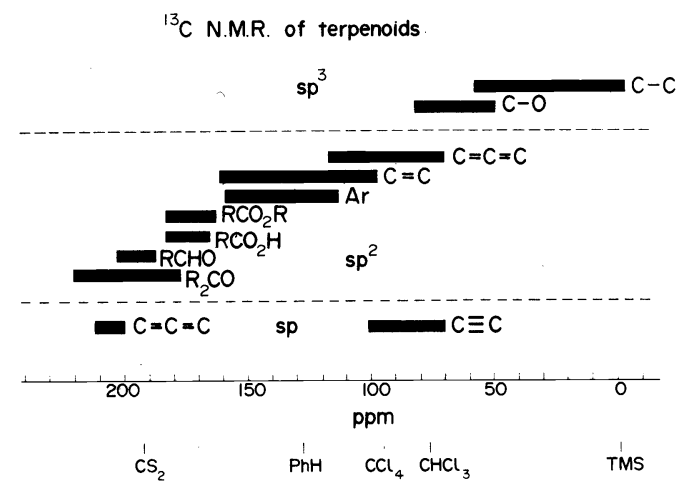

Fig. 1. Chemical shifts observed in terpenoids (ppm from $\delta_{\mathrm{TMS}}=0$ ) according to hybridisation of the carbon atom (top sp ${ }^{3}$, middle $\mathrm{sp}^{2}$, bottom $\mathrm{sp}$ ). 


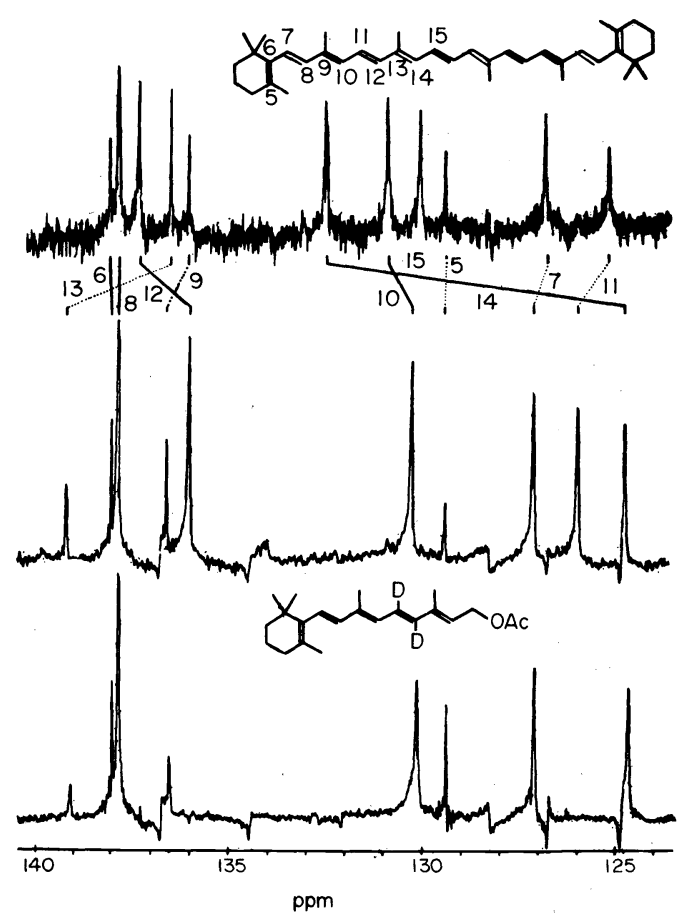

Fig. 2. $\mathrm{sp}^{2}$ Region of the ${ }^{13} \mathrm{C}$-NMR spectra of $\beta$-carotene (top curve), vitamin $A$ acetate (middle curve) and $\left[11,12-{ }^{2} \mathrm{H}_{2}\right]$ vitamin $A$ acetate (bottom curve).

chain by the carbonyl group (Table 1). Using these data the assignment of 9-cis and 13-cis vitamin A acetate is quite straightforward, and hence also $\beta$-carotene (Table 1). These results also demonstrate the relatively constant changes observed between the spectra of cis and trans isomers.

\section{B-APO CAROTENOIDS}

The assignment of the $\beta$-carotene spectrum was confirmed by a study of a series of methyl $\beta$-apo carotenoates (Fig. 3). Polarisation of the polyene chain by the carbonyl group results in strong shielding of the $\alpha$-position (and progressively less at $\gamma, \epsilon$ etc.) and strong deshielding at the $\beta$-position (and progressively less at $\delta, \xi$ etc.). $\beta$-Carotene thus represents the limiting values for these signals. In most cases SFOR data was used to confirm C-5, C-6, C-9 and $\mathrm{C}-13$. Some variation in the signals was observed, possibly due to concentration effects. ${ }^{3}$

A limited study by Bremser and Paust ${ }^{7}$ of a number of $\beta$-apocarotenals and ketones came to similar conclusions (except for C-9 and C-13). Detailed studies of the ${ }^{13} \mathrm{C}-\mathrm{NMR}$ spectrum of retinal by Rowan and Sykes, ${ }^{8}$ and by Becker $e t$ al. ${ }^{9}$ also show minor variations from Bremser and $\mathrm{Paust}^{7}$ in the assignment of $\mathrm{C}-10$, although there are solvent differences (See also ref. (27)). The differences in chemical shift between spectra run in acetone and cyclohexane ${ }^{8}$ parallel our experience of concentration and solvent effects ${ }^{3}$ where the significant changes occur at the carbonyl and $\beta$-signal, and less so with the $\delta$ - and $\xi$-signals. Although the $\alpha$-signal may be just affected most other signals are unchanged. The original assignment of $\alpha$-and $\beta$-ionone ${ }^{5}$ has been revised by Hollenstein and von Philipsborn ${ }^{10}$ and later workers. ${ }^{8,11}$

\section{ZEAXANTHIN, ISOZEAXANTHIN, ISOCRYPTAXANTHIN, VIOLAXANTHIN AND ALLOXANTHIN}

The effect on the ${ }^{13} \mathrm{C}$-NMR spectrum of substitution of a cyclohexane ring by a hydroxyl group has been studied by Roberts et al. ${ }^{12}$ Using his parameters the spectrum of zeaxanthin (II) is readily interpreted (Table 1). As expected the changes from the spectrum of $\beta$-carotene imply a predominantly equatorial hydroxyl group. Similarly the spectrum of isozeaxanthin (III) also can be readily assigned (Table 1). In this case a pseudo axial hydroxyl group is suggested, possibly implying that when the hydroxyl

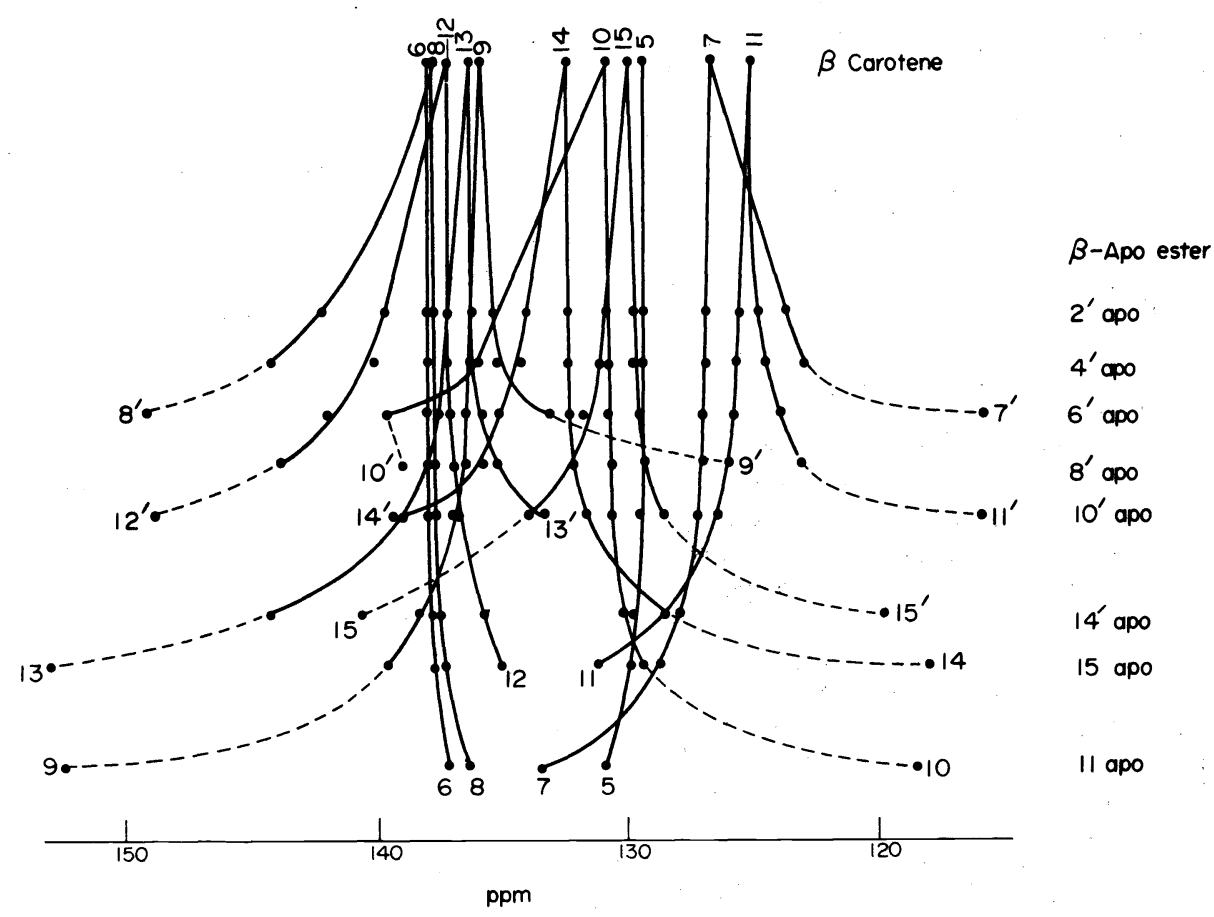

Fig. 3. Graph of $\mathrm{sp}^{2}$ chemical shifts of $\beta$-carotene and methyl $\beta$-apo carotenoates. Vertical scale represents increasing number of double bonds $(n)$ with $\beta$-carotene effectively $n=\infty$. 


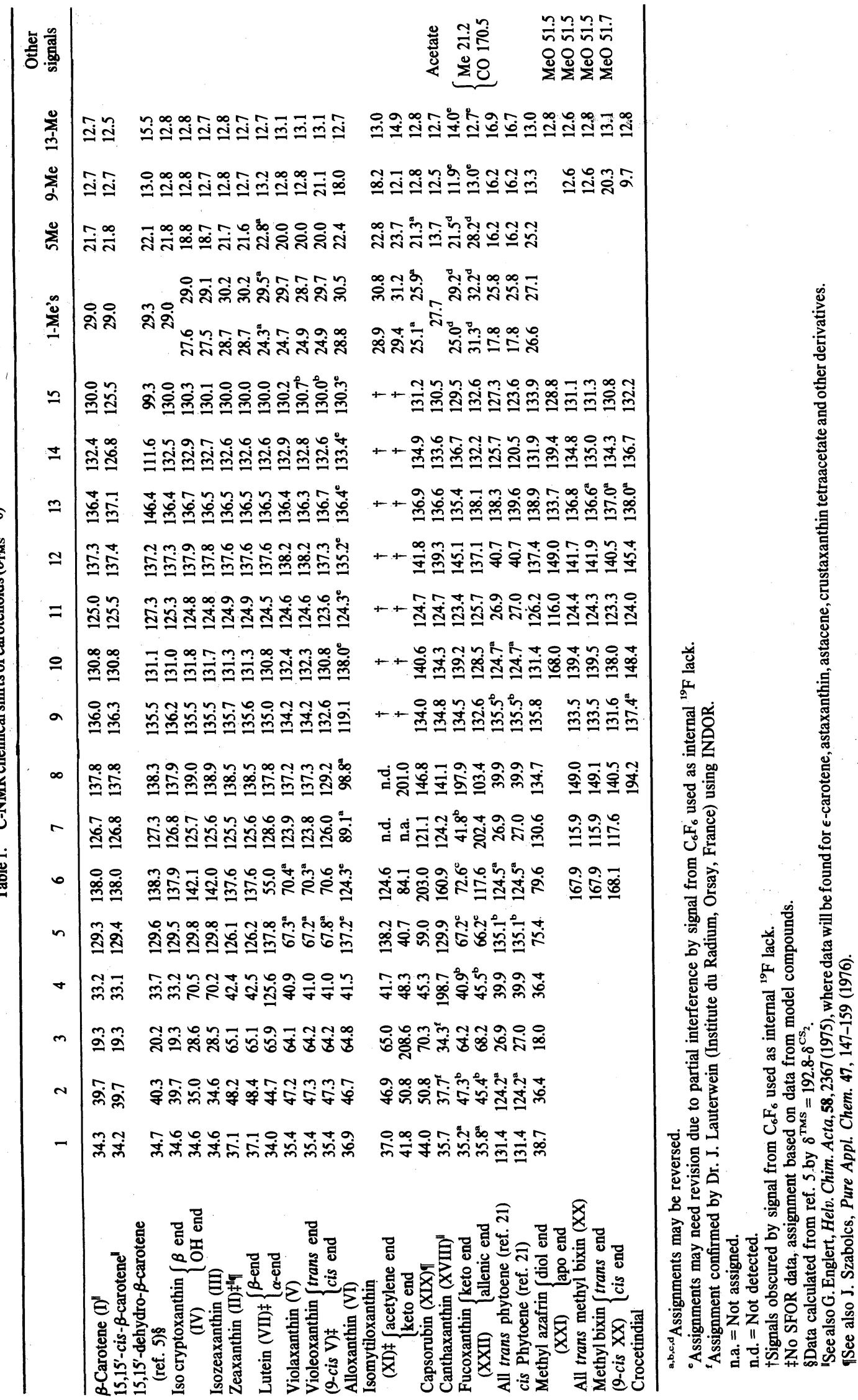


<smiles>[R]C(C)=CC=CC(C)=CC=CC=C(C)C=CC=C([R])C</smiles><smiles>C/C=C/C1=C(C)CCCC1(C)C</smiles>

a<smiles>CC=CC1=C(C)C(O)CCC1(C)C</smiles>

c<smiles>CC#CC1=C(C)CC(O)CC1(C)C</smiles>

e<smiles>C/C=C/C1=C(C)CC(O)CC1(C)C</smiles>

b

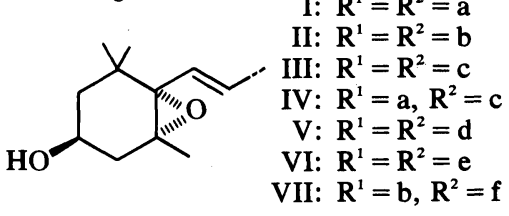

d<smiles>C/C=C/C1C(C)=C[C@@H](O)CC1(C)C</smiles>

group is in a pseudoequatorial conformation it eclipses the 5-methyl group. With the symmetric carotenoids considered above there are only half as many carbon signals as would be expected with a pigment such as isocryptoxanthin (IV). However the spectrum is exactly as expected from a combination of the spectra found for each end group. Violaxanthin $(\mathrm{V})$, the natural diepoxide of zeaxanthin, only shows small spectral changes except for C-5 and C-6 (Table 1). Similarly the 7,8-dehydro system of alloxanthin (VI) only slightly modifies the position of the $\mathrm{sp}^{3}$ signals of zeaxanthin, and shows typical changes in the $\mathrm{sp}^{2}$ region (cf. 15,15'-dehydro- $\beta$-carotene, Table 1).

\section{LUTEIN AND ISOMYTILOXANTHIN}

The results discussed above are only concerned with the assignment of signals from the spectra of fully characterised carotenoids. However, ${ }^{13} \mathrm{C}$-NMR spectroscopy can provide stereochemical and structural information. As I reported at $\mathrm{Cluj}^{13}$ the problem of the stereochemistry and conformation of the $3^{\prime}$ and $6^{\prime}$ substituents of lutein (VII) trans model (VIII) show that the alkyl (polyene) group at C-6 is equatorial, and with the cis model IX axial (Table 2). The effect at C-2 is particularly diagnostic. These conclusions have since been confirmed by several groups. ${ }^{15-17}$

A tentative assignment of isomytiloxanthin (XI) was reported at $\mathrm{Cluj}^{18}$ (Table 1). It was based on data from the model compounds XII and XIII with the stereochemistry shown. This data, ${ }^{1} \mathrm{H}-\mathrm{NMR}$ studies and the biogenesis suggest that isomytiloxanthin has the opposite stereochemistry at C-6 from the model compounds.

\section{CIS ISOMERS OF CAROTENOIDS AND RELATED COMPOUNDS}

$C$ is isomers were used in the full assignment of $\beta$ carotene (vide supra). The characteristic shifts associated with a cis trisubstituted double bond are summarised on formula XV.

Violeoxanthin was shown by Szabolcs and Tóth ${ }^{19}$ to be a cis isomer of violaxanthin (V). The position of the cis double bond was most clearly demonstrated to be at C-9, $\mathrm{C}-10$ by the ${ }^{13} \mathrm{C}-\mathrm{NMR}$ spectrum of violeoxanthin ${ }^{20}$ (Table<smiles>CC(O)/C=C/C1CC2CC(O)CC1C2(C)C</smiles>

VIII

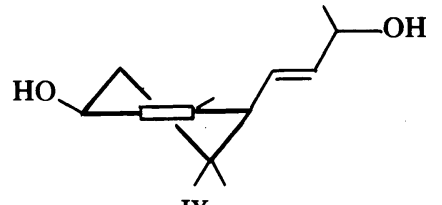

IX<smiles>[X]C1=CC(O)CC(C)(C)C1</smiles>

$\mathrm{X}$ can be demonstrated from a comparison of the spectrum with model compounds. Both isomers of 3-hydroxy- $\alpha$ ionol $\dagger$ (VIII and IX) were prepared and one related to the $\epsilon$-end of lutein by both ${ }^{1} \mathrm{H}$ and ${ }^{13} \mathrm{C}$ NMR spectroscopy (Table 2). The $\beta$-end of lutein gave signals which were readily identified using the spectrum of zeaxanthin (Table 1). Lutein and the model compounds must have a preferred conformation with the 3-hydroxy groups equatorial to minimise interactions with the 1-methyls. Comparison of the spectrum of $\alpha$-isophorol (X) with those of lutein and the

†Carotenoid numbering.
1); especially by the characteristic shifts of the 9-methyl and $\mathrm{C}-8$ signals.

In a study of the $\beta-\mathrm{C}_{15}$-Wittig salt (XIV) the spectrum is complicated by the additional phenyl signals, and the presence of ${ }^{13} \mathrm{C}-{ }^{31} \mathrm{P}$ spin-spin coupling. In order to pair the signals split by ${ }^{13} \mathrm{P}$ the spectra were run at both $22.63 \mathrm{MHz}$ and $25.15 \mathrm{MHz}$ so that changes in the positions of the signals could be distinguished from the constant coupling constants. Both the 9-cis and 9-trans Wittig salt were examined and typical changes observed. However the most interesting feature of these spectra were the long range ${ }^{13} \mathrm{C}-{ }^{31} \mathrm{P}$ couplings. With the zig-zag $\pi$ system of the trans isomer the coupling is transmitted over up to six 
Table 2. ${ }^{13} \mathrm{C}$-NMR data for the $\epsilon$-end of lutein and related models

\begin{tabular}{|c|c|c|c|c|c|c|c|}
\hline & & 1 & 2 & 3 & 4 & 5 & 6 \\
\hline$\delta$ & Lutein (VII) & 34.0 & 44.7 & 65.9 & 125.6 & 137.8 & 55.0 \\
\hline$\delta$ & trans diol (VIII) & 34.2 & 45.5 & 66.4 & 125.9 & 137.8 & 55.0 \\
\hline$\delta$ & cis diol (IX) & 35.2 & 41.3 & 67.3 & 126.0 & 138.0 & $55.0 \dagger$ \\
\hline$\delta$ & $\alpha$-isophorol (X) & 31.3 & $45.4 \ddagger$ & 66.7 & 124.7 & 135.2 & $44.7 \ddagger$ \\
\hline$\Delta \delta$ & VII-X & 2.7 & -0.7 & -0.8 & 0.9 & 2.6 & 10.3 \\
\hline$\Delta \delta$ & VIII-X & 2.9 & 0.1 & -0.3 & 1.2 & 2.6 & 10.3 \\
\hline$\Delta \delta$ & IX-X & 3.9 & -4.2 & 0.6 & 1.3 & 2.8 & 10.3 \\
\hline$\Delta \delta$ & 6-equatorial $\mathrm{Me}$ (ref. 14) & 9.03 & 0.05 & -0.22 & 0.05 & 9.03 & 5.96 \\
\hline$\Delta \delta$ & 6-axial Me (ref. 14) & 5.41 & -6.37 & -0.06 & -6.37 & 5.41 & 1.40 \\
\hline
\end{tabular}

$\dagger$ †verage of two signals $(54.9,55.1)$, due to diastereoisomers differing at C-9.

$¥$ Assignment may be reversed.<smiles>CC(C#CC1=C(C)CC(O)CC1(C)C)=C/C=C/C=C/C=C/C=C/C(C)=C/C=C/C=C(C)C(=O)C[C@]1(O)[C@@H](C)CC(=O)CC1(C)C</smiles>

XI

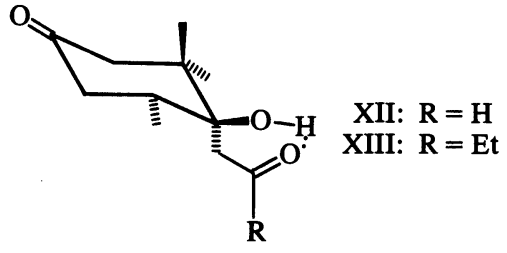

bands. In contrast the cis double bond of the other isomer does not allow such an extended zig-zag chain so that coupling only occurs over four bonds (Table 3 ).

The other relatively stable positions for a cis double bond is at $15,15^{\prime}$. To examine the effect of isomerisation at this position the spectra of $15,15^{\prime}$-cis- $\beta$-carotene and a $\left[15,15^{\prime}-{ }^{2} \mathrm{H}_{2}\right]$ labelled sample were analysed. $\mathrm{C}-15$ was readily identified by the 'missing' signals in the spectrum of the labelled material, and comparison with the data for all trans - $\beta$-carotene readily suggested a complete assignment (Table 1). The changes are summarised on formula XVI. These figures show that the assignments by Granger $e t$ al. ${ }^{21}$ of $\mathrm{C}-13$ and $\mathrm{C}-15$ of the phytoene isomers should be reversed. The remaining ambiguities left with the phytoene spectra are not resolved even with the extensive studies of related systems by Crombie et al. ${ }^{22}$

The changes observed ${ }^{8,9}$ between trans retinal and the hindered 11-cis isomer (see formula XVII) show that the<smiles>CC1=C(/C=C/C(C)=C/C[PbH2])C(C)(C)CCC1</smiles>

position of any isolated cis double bond should be readily recognised from the ${ }^{13} \mathrm{C}-\mathrm{NMR}$ spectrum.

\section{CANTHAXANTHIN, CAPSORUBIN, AZAFRIN AND FUCOXANTHIN}

The effect of a carbonyl group on the spectra of methyl $\beta$-apo-carotenoates (Fig. 3) has already been commented on. A keto group at C-4 and C-4' of $\beta$-carotene (canthaxanthin XVIII) polarises the polyene chain and greatly assists the assignment of the $\mathrm{sp}^{2}$ signals (Table 1), while data from model compounds ${ }^{23,24}$ supports the $\mathrm{sp}^{3}$ assignments. The chromophore of capsorubin (XIX) is essentially the same as trans methyl bixin (XX). Comparison of their spectra (Table 1) shows this similarity apart from slight differences in the signals of carbon atoms adjacent to the carbonyl group. The remaining $\mathrm{sp}^{3}$ carbons are assigned by comparison with the spectrum of helicobasidin ${ }^{25}$ and related models.

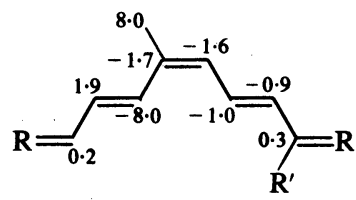

$\mathrm{XV}$

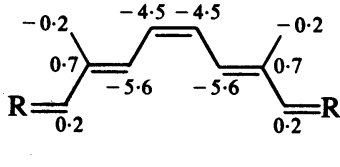

XVI

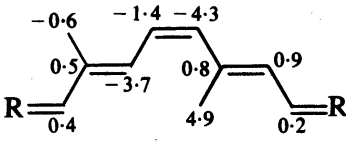

XVII

Table 3. ${ }^{13} \mathrm{C}$-NMR data for $\beta-\mathrm{C}_{15}$ Wittig salt

\begin{tabular}{lrrrrrrr}
\hline & \multicolumn{1}{c}{6} & \multicolumn{1}{c}{7} & \multicolumn{1}{c}{8} & \multicolumn{1}{c}{9} & \multicolumn{1}{c}{10} & \multicolumn{1}{c}{11} & $9-\mathrm{Me}$ \\
\hline$\delta$ 9-trans XIV & 139.9 & 128.6 & 135.4 & 143.7 & 112.5 & 24.7 & 12.8 \\
$\delta \Delta(9$ cis-9 trans $)$ & -2.2 & 3.2 & -7.1 & -2.5 & 0.8 & -1.1 & 8.1 \\
$J_{13} \mathrm{c}^{31} \mathrm{p}(\mathrm{Hz}) 9-$-trans & 2.4 & 5.0 & 6.0 & 14.1 & 11.3 & 49.2 & 2.5 \\
$J_{13} \mathrm{c}^{31} \mathrm{p}(\mathrm{Hz})$ 9-cis & & & 2.5 & 12.5 & 11.3 & 51.3 & \\
\hline
\end{tabular}




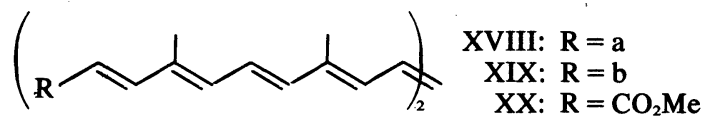<smiles>CC1=C(C)C(C)(C)CCC1=O</smiles><smiles>CC(=O)[C@]1(C)C[C@@H](O)CC1(C)C</smiles>

a<smiles>COC(=O)/C=C/C(C)=C/C=C/C=C(C)/C=C/C=C(C)/C=C/[C@]1(O)[C@H](O)CCCC1(C)C</smiles>

XXI<smiles>CC(=O)O[C@H]1CC(C)(C)C(=C=CC(C)=CC=CC(C)=CC=CC=C(C)C=CC=C(C)C(=O)C[C@@]23O[C@]2(C)C[C@@H](O)CC3(C)C)[C@@](C)(O)C1</smiles>

XXII

Methyl $\beta$-apo-10'-carotenoate is a good model for the assignment of the $\mathrm{sp}^{2}$ region of the spectrum of methyl azafrin (XXI). In order to identify the $\mathrm{sp}^{3}$ signals an analysis of the substituent effects expect ${ }^{12,14,26}$ for the cyclohexane ring with a diaxial glycol conformation ${ }^{18}$ were calculated and found to predict the observed values (Table 1) quite closely.

Fucoxanthin (XXII) is an interesting case where 41 of the 42 expected signals are clearly resolved. ${ }^{1}$ The expected effect of the carbonyl group and SFOR data readily allows an assignment of the $\mathrm{sp}^{2}$ signals. However apart from the division into categories using SFOR data there are too few spectra derived from model compounds to assist the assignment of either end group.

Acknowledgements - Finally I should like to thank those who have been associated with this work; in particular Professor B. C. L. Weedon for his encouragement and the supply of precious samples, Professor E. W. Randall for access to the Bruker HFX 90 spectrometer and my principal collaborator in this work, Mr. J. F. Hagel. My thanks are also due to Dr. P. S. Pregosin for some of the earlier spectra; Mr. G. M. Leeder, Roche Products Ltd., Welwyn Garden City, $\left(25.15 \mathrm{MHz}\right.$ spectra, of the $\mathrm{C}_{15}$ Wittig salts and samples); Dr. G. M. Clarke, Roche Products Ltd., Welwyn Garden City, (cis vitamin A acetates); Dr. O. Isler, Hoffman-La Roche \& Co. Ltd., Basle, ([11,12- $\left.{ }^{2} \mathrm{H}_{2}\right]$ vitamin A acetate); Dr. A. Khare, (preparation of isomytiloxanthin models); Mr. D. Goodfellow (preparation of lutein models); Miss E. A. H. Hall (preparation of $\left[15,15^{\prime}-{ }^{2} \mathrm{H}_{2}\right] 15,15$-cis - $\beta$-carotene).

\section{REFERENCES}

${ }^{1}$ G. P. Moss and B. C. L. Weedon, in Chemistry and Biochemistry of Plant Pigments. 2nd Edn, Chap. 3 (editor T. W. Goodwin), Academic Press, New York (1976).

${ }^{2}$ G. C. Levy and G. L. Nelson, Carbon-13 Nuclear Magnetic Resonance for Organic Chemists. Wiley Interscience, New York (1972); J. B. Stothers, Carbon-13 NMR Spectroscopy. Academic Press, New York (1972); L. F. Johnson and W. C. Jankowski, Carbon-13 NMR Spectra. Wiley Interscience, New York (1972); E. Breitmaier and W. Voelter, ${ }^{13} \mathrm{C}$ NMR Spectroscopy. Verlag Chemie (1974).
${ }^{3}$ J. F. Hagel and G. P. Moss, unpublished results.

${ }^{4}$ W. Vetter, G. Englert, N. Rigassi and U. Schwieter, in Carotenoids. Chap. 4, (editor O. Isler), Birkhäuser, Basle (1971).

${ }^{5}$ M. Jautelat, J. B. Grutzner and J. D. Roberts, Proc. Nat. Acad. Sci. U.S.A. 65, 288 (1970)

${ }^{6}$ W. Bremser, H. D. W. Hill and R. Freeman, Messtechnik, 79, 14 (1971).

${ }^{7}$ W. Bremser and J. Paust, Org. Mag. Res. 6, 433 (1974).

${ }^{8}$ R. Rowan III and B. D. Sykes, J. Am. chem. Soc. 96, 7000 (1974).

${ }^{9}$ R. S. Becker, S. Berger, D. K. Dalling, D. M. Grant and R. J. Pugmire, J. Am. chem. Soc. 96, 7008 (1974).

${ }^{10} \mathrm{R}$. Hollenstein and W. von Philipsborn, Helv. Chim. Acta, 55, 2030 (1972).

${ }^{11}$ A. K. Bose and P. R. Srinivasan, Tetrahedron Lett. 1571 (1975).

${ }^{12}$ J. D. Roberts, F. J. Weigert, J. I. Kroschwitz and H. J. Reich, J. Am. chem. soc. 92, 1338 (1970).

${ }^{13}$ D. Goodfellow, G. P. Moss and P. S. Pregosin, unpublished results.

${ }^{14}$ D. K. Dalling and D. M. Grant, J. Am. chem. Soc.94, 5318(1972).

${ }^{15}$ R. Buckecker, P. Hamm and C. H. Eugster, Helv. chim. Acta, 57, 631 (1974).

${ }^{16}$ A. G. Andrewes, G. Borch and S. Liaaen-Jensen, Acta chem. Scand. B28, 139 (1974).

${ }^{17}$ B. C. L. Weedon, Pure Appl. Chem. 47, 161-171.

${ }^{18}$ B. C. L. Weedon, Pure Appl. Chem. 35, 113 (1973).

${ }^{19} \mathrm{~J}$. Szabolcs and Gy. Tóth, Acta chim. Acad. Sci. Hung. 63, 229 (1970).

${ }^{20}$ G. P. Moss, J. Szabolcs, Gy. Tóth and B. C. L. Weedon, Acta chim. Acad. Sci. Hung. 87, 301 (1975).

${ }^{21}$ P. Granger, B. Maudinas, R. Herber and J. Villoutreix, J. Mag. Res. 10, 43 (1973)

${ }^{22}$ L. Crombie, R. W. King and D. A. Whiting, J. Chem. Soc. Perkin I, 913 (1975).

${ }^{23}$ F. J. Weizert and J. D. Roberts, J. Am. chem. Soc. 92, 1347 (1970).

${ }^{24}$ G. Magnusson and S. Thorén, J. Org. Chem. 38, 1380 (1973).

${ }^{25} \mathrm{M}$. Tanabe, K. T. Suzuki and W. C. Janowski, Tetrahedron Lett. 4723 (1973).

${ }^{26}$ H. Ziffer, J. I. Seeman, R. J. Highet and E. A. Sokoloski, J. Org. Chem. 39, 3698 (1974).

${ }^{27}$ Y. Inoue, A. Takahashi, Y. Tokitô, R. Chûjô and Y. Miyoshi, Org. Mag. Res. 6, 487 (1974). 